\title{
Heaney's hysterectomy for benign pathological conditions of uterus at tertiary care hospital in southern India
}

\author{
Sudha. $\mathbf{R}^{1, *}$, Umashankar $^{2}$, Dharmavijay ${ }^{3}$ \\ ${ }^{\mathbf{1}}$ Assistant Professor, Dept. of Obstetrics and Gynaecology, East Point College of Medical Sciences, Hirandahalli, Bangalore, \\ Karnataka, ${ }^{2}$ Assistant Professor, ${ }^{3}$ Professor, Dept. of Obstetrics and Gynaecology, MVJ Medical College and Research Hospital, \\ Hoskote, Bangalore, Karnataka, India
}

*Corresponding Author:

Email: sudha.chinnu@gmail.com

Received: $14^{\text {th }}$ April, 2018

Accepted: $26^{\text {th }}$ April, 2018

\begin{abstract}
Introduction: Hysterectomy is one of the commonly performed gynaecological surgery. Vaginal hysterectomy is a natural orifice surgery where as laparoscopic hysterectomy is a minimally invasive procedure. Vaginal hysterectomy is associated with less morbidity, less operative time, short duration of hospital stay and reduced cost compared to laparoscopy. With increasing containment of health care costs and epidemic increase of non communicable medical disorders there is a need for performing vaginal hysterectomy in benign non prolapsed uteri especially in rural settings.

Aims and Objectives: The objective of this study is to know the intra operative factors and to study the short term outcomes associated with non descent vaginal hysterectomy \{Heaney's hysterectomy .

Materials and Methods: This is prospective observational study conducted at MVJ Medical College and Research Hospital located in rural setting from January 2012 to December 2012. All the patients requiring hysterectomy for benign conditions not associated with uterine descent underwent non descent vaginal hysterectomy. Intra operative factors like blood loss, difficulty in delivery of uterus, bowel and bladder injuries, and conversion rates to laparotomy were noted. Post operative complications were noted.

Results: Seventy two patients were planned to undergo non descent vaginal hysterectomy for various benign conditions. Vaginal hysterectomy was done successfully in 70 patients. The mean age was $45.6 \pm 3.4$ and mean parity was $2.2 \pm 0.45$. Dysfunctional uterine bleeding $(55 \%)$ was the most common indication. Average duration of surgery was $45-80$ min. The requirement of post operative analgesia was minimal by the patient as there was no abdominal incision. Post operative complications were less. The duration of hospital stay was 3-5 days.

Conclusions: Non descent vaginal hysterectomy is less invasive surgery. Less morbidity, lesser duration of hospital stay, cost effectiveness makes vaginal route as the choice for women in rural settings.
\end{abstract}

Keywords: Heaney's hysterectomy, Benign pathology.

\section{Introduction}

Hysterectomy is one of the commonly performed gynecological surgeries. It can be accomplished by different routes like transabdominal, vaginal and through laparoscopy. Traditionally majority of hysterectomies were done by opening the abdomen and vaginal hysterectomy was reserved for uterine descent. With evidence showing the advantages of vaginal hysterectomy there is reemerging interest to perform vaginal hysterectomy in every patient requiring hysterectomy for benign disease. Selection of the route of hysterectomy for benign causes is influenced by the size of uterus, mobility of the uterus, prescence of extrauterine pathology, the need for concurrent procedures like oophorectomy, salpingectomy, training and experience of the surgeon, average case volume, availability of hospital technical support, whether the case is emergency or elective and preference of the patient. ${ }^{1}$ Laparoscopic hysterectomy is minimally invasive and vaginal hysterectomy is natural orifice surgery. Since the introduction of laparoscopy in 1990s, it has gained popularity but it is associated with increased cost, longer duration of operation, special instruments and specially trained person there is risk of exposure to general anasthesia. On the other side vaginal hysterectomy is associated with less morbidity, less operative time, lesser duration of hospital stay and less cost. Non descent vaginal hysterectomy is the removal of uterus through vagina in the absence of descent of the cervix. For some time in history non descent vaginal hysterectomy was considered unacceptable. ${ }^{2}$ With increasing awareness of the advantages associated with the vaginal hystetectomy, vaginal approach is considered as the ideal and natural route to explore the uterus. With increasing containment of health care costs there is need for performing vaginal hysterectomy in benign non prolapsed uteri especially in rural settings in view of less cost and less duration of hospital stay. The objective of this study is to try to perform vaginal hysterectomy for benign conditions not associated with prolapse, to study the intra operative factors and to study the short term outcomes of surgery. 


\section{Materials and Methods}

The study was a prospective observational study conducted in the Department of Obstetrics and Gynecology at MVJ Medical College and Research Hospital located in rural setting. Study period is from January 2012 to December 2012. Patients requiring hysterectomy for benign conditions without uterine descent were admitted and after pre operative evaluation and pre anaesthetic check up, underwent non descent vaginal hysterectomy.

\section{Exclusion Criteria}

Size of uterus more than 16 weeks gravid uterus

Restricted mobility

Uterine desent

Pelvic endometriosis

Previous pelvic surgery

Genital malignancy

Complex adnexal mass

Informed consent was taken prior to the surgery after counseling regarding method of surgery and possibility of conversion to abdominal route if required.

Operative Details: Inj. Cefotaxime 1gm IV stat one hour prior to the surgery for antiobiotic prophylaxis after test dose.

Surgery was done under regional anaesthesia, spinal or combined with epidural anaethesia. Mobility of the uterus was checked under anaesthesia.

With patient in dorsal lithotomy position a circular incision is made around the cervix and vesicovaginal space dissection done. The vesicocervical ligament is cut, vesicocervical space exposed and bladder pushed upwards. Posterior peritoneum opened. After this mackenrodts and uterosacral ligaments cut and transfixed. Then uterine vessels cut and transfixed. Third clamp applied to adnexal structures, cut and transfixed. Uterus delivered. In cases of difficulty in applying clamps or delivery, bisection morcellation and myomectomy were done as was needed. Stumps were checked for haemostasis and vault closed. The time of operation was calculated from the time of incision to the end of vault closure. The following parameters were assessed.

1. Intra operative blood loss - blood loss was measured by counting the number of mops and blood collected in the suction reservoir.

2. Time taken for surgery: From the time of incision to the end of vault closure.

3. Intraoperative complications: Injury to bowel, bladder and ureter is noted.

4. Postoperative blood transfusion depending on the repeat hemoglobin after $24 \mathrm{hrs}$ of operation.

5. Postoperatively temperature is charted 4th hourly. Fever is defined as temperature more than or equal to 38 degree Celsius on 2 occasions 4 hours apart excluding the first day.
6. Wound infection- Presence of foul smelling discharge per vagina were followed up till date of discharge from hospital.

7. Any other form of infection like respiratory tract infection, urinary tract infection is noted.

8. Duration of hospital stay is noted.

All patients were discharged $3^{\text {rd }}-5^{\text {th }}$ day post operative day and advised to visit out patient clinic 2 weeks later.

Statistical analysis was done using spss software.

\section{Results}

72 patients were planned to undergo non descent vaginal hysterectomy for various benign conditions. Non descent vaginal hystetrctomy was successfully performed in 70 patients. Majority of the patients were aged between $40-50$ yrs. The mean age with standard deviation was $45.63 \pm 3.4$. The mean parity was $2.2 \pm$ 0.45 as depicted in table 1 . The most common indication for hysterectomy was dysfunctional uterine bleeding not responding to medical management.

\section{Table 1: Patient characteristics}

\begin{tabular}{|l|c|}
\hline & Mean \pm SD \\
\hline Age in yrs & $45.63 \pm 3.4$ \\
\hline Parity & $2.2 \pm 0.45$ \\
\hline
\end{tabular}

Table 2: Different indications for non descent vaginal hysterectomy

\begin{tabular}{|l|c|}
\hline \multicolumn{1}{|c|}{ Indications } & No of cases (\%) \\
\hline $\begin{array}{l}\text { Dysfunctional uterine } \\
\text { bleeding }\end{array}$ & $40(55.55)$ \\
\hline Chronic PID & $15(20.83)$ \\
\hline Fibroid uterus & $10(13.88)$ \\
\hline Adenomyosis & $5(6.94)$ \\
\hline Endometrial hyperplasia & $2(2.77)$ \\
\hline
\end{tabular}

Table 3: Size of the uteri in weeks assessed clinically

\begin{tabular}{|c|c|}
\hline $\begin{array}{c}\text { Size of uterus in } \\
\text { weeks }\end{array}$ & Number (percentage) \\
\hline Normal & $38(52.77)$ \\
\hline$<8$ & $15(20.83$ \\
\hline $8-12$ & $17(23.6$ \\
\hline$>12$ & $2(2.77)$ \\
\hline
\end{tabular}

Table 4: Size reduction techniques used to ease removal of uterus

\begin{tabular}{|l|c|}
\hline Size reduction & No of cases (\%) \\
\hline Complete & $60(83.33)$ \\
\hline Bisection & $6(8.33)$ \\
\hline Myomectomy & $4(5.55)$ \\
\hline Morcellation & $2(2.77)$ \\
\hline
\end{tabular}

In the present study mean blood loss was $100-150$ $\mathrm{ml}$. The duration of surgery varied from $45-80 \mathrm{~min}$. Eight patients required blood transfusion. In two patients Laparotomy was needed, one patient because 
of bowel injury and the other patient because of difficult delivery of uterus vaginally.

Table 5: Post operative morbidity

\begin{tabular}{|l|c|}
\hline \multicolumn{1}{|c|}{ Post operative morbidity } & Number \\
\hline None & 60 \\
\hline Fever & 6 \\
\hline Urinary tract infection & 6 \\
\hline
\end{tabular}

The requirement of analgesia was minimal as there was no abdominal incision. The duration of hospital stay was 3 to 5 days.

\section{Discussion}

Traditionally $70-80 \%$ of hysterectomies were performed by opening the abdomen and vaginal hysterectomy was reserved for patients with genital prolapse. With the practice of laparoscopy, laparoscopic removal of uterus gained popularity at the cost of extensive learning curve, expensive procedure cost. In this era of minimally invasive surgery vaginal hysterectomy is scarless, associated with lesser intraoperative complications, less post operative morbidity and cost effective.

In the our study majority were majority were aged between 40-50yrs with mean age being 45yrs and majority were multipara as comparable to study by Kalpana Mehta. ${ }^{3}$ Dysfunctional uterine bleeding attributed to $55.5 \%$ of non descent vaginal hysterectomy which is comparable to multi-centric study done by Chaitra Ramachandra et al. ${ }^{4}$ In the study done by Dewan et $\mathrm{al}^{5}$ fibroid uterus was the most common indication in contradiction to our study.

In the present study 70 patients underwent non descent vaginal hysterectomy among which 12 patients required de bulking methods like bisection, myomectomy and morcellation. Similar techniques were applied in the study done by Banasree Bhadra. ${ }^{6}$ Two cases required conversion to laparotomy. One patient had bowel injury for which laparotomy and repair was done. Second patient required laparotomy for difficult delivery of the uterus.

Duration of surgery was varied between 45-80 minutes which is comparable to other studies done by Bhadra $\mathrm{B}$ et al (55.5 minutes) ${ }^{6}$ Dewan et al (54 minutes $),{ }^{5}$ Bharatnur et al (65.5 minutes). ${ }^{7}$ It depends on the size of the uterus and experience of the surgeon. The length of hospital stay reported by Dorsey et al was 3.5 for total vaginal hysterectomy. In our study hospital stay was 3-5 days which is comparable to the study done by Gayathri KB et al. ${ }^{8}$ Vaginal route is possible in majority of cases with benign pathology and should be attempted as its minimal invasive and has faster recovery compared to abdominal approach. hysterectomy is an special surgical procedure with unique challenges. Proper preoperative assessment and examination under anaesthesia are crucial before Heaney's hysterectomy. In experienced hands Heaney's hysterectomy is feasible in majority of the cases and is associated with less complications, less morbidity and rapid recovery with good quality of life in post operative. Vaginal hysterectomy is cost effective compared to abdominal and laparoscopic hysterectomy. Majority of the hysterectomies should be performed vaginally in the best interest of patient especially in the rural setting where the patient come from poor socioeconomic status and who are into physical activities like weight lifting.

\section{References}

1. ACOG committee opinion no 701. Choosing the route of hysterectomy for benign diseases. June 2017.

2. Davies A, Wizza E, Bournas N. How to increase the proportion of hysterectomies performed vaginally. Am J Obstet Gynecol. 1998;179:1008-12.

3. Kalpana Mehta, Om Prakash, Dharmendra Singh Fatehpuriya, Leena Verma. Comparative study of abdominal hysterectomy and vaginal hysterectomy in non-descent cases a prospective study. International Journal of Reproduction, Contraception, Obstetrics and Gynecology. 2017;6(4):1265-1270.

4. Chaitra Ramachandra, Ramlingappa, Deepa, Shankaregowda (2016). Vaginal Hysterectomy for non descent Uterus- A Prospective Multicentric Study. Women's Health \& Gynecology 2016;2(5):034.

5. R. Dewan, S. Agarwal, B Minocha, S.K. Sen, Nondescent Vaginal Hysterectomy - An Experience. Journal of Obstetrics and Gynecology of India. 2004;54(4):376378.

6. Banasree Bhadra, Arun Paul Choudhury, Amit Tolasaria and Nandi Nupur (2011). Non Descent Vaginal Hysterectomy (NDVH): Personal Experience in 158 Cases. Al Ameen Journal of Medical sciences. 2011;4 (1):2 3 -2 7

7. S. Bharatnur S, Comparative study of abdominal versus vaginal hysterectomy in Non-Descent cases. The internet journal of Gynaecology and Obstetrics. 2011;15(2);15281539.

8. Dorsey JH, Steinberg EP, Holtz PM. Clinical indications for hysterectomy route: patient characteristic or physician preference. Am J Obstet Gynaecol. 1995;173(5):1452-60.

9. Gayathri KB, Sajana G, Manjusha P, Bhargav PRK. Non Descent Vaginal Hysterectomy (NDVH) for Benign Gynaecological disease: An Institutional Study on safety and feasibility from South India. IOSR Journal of Dental and Medical Sciences (IOSR-JDMS). 2017;16(11)Ver.VII:59-63.

How to cite this article: Sudha .R, Umashankar, Dharmavijay. Heaney,s hysterectomy for benign pathological conditions of uterus at tertiary care hospital in southern India. Ind J Obstet Gynecol Res. 2018;5(3):389-391.

\section{Conclusions}

Vaginal hysterectomy is the natural orifice surgery so is superior to minimally invasive surgery. Heaney's 